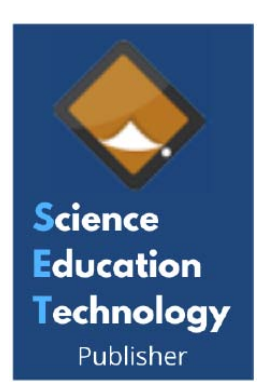

\title{
Effect of Soy Isoflavones Supplementation on Adiponectin Levels in Postmenopausal Women: A Meta-Analysis
}

\author{
Sara Tutunchi ${ }^{1}$, Mehdi Koushki ${ }^{2}$, Nasrin Amiri-Dashatan ${ }^{3}$, Hadi Khodabandehloo ${ }^{2}$, Hossein \\ Hosseini $^{4}$, Ghodratollah Panahi ${ }^{4}$, Javad Hashemi ${ }^{5}$, Amir Karbalaee-Hasani ${ }^{2}$, Ziba Majidi ${ }^{4}$ and \\ Mostafa Rezaei-Tavirani, ${ }^{3,}$
}

${ }^{1}$ Department of Medical Genetics, Shahid Sadoughi University of Medical Sciences, Yazd, Iran; ${ }^{2}$ Department of Clinical Biochemistry, School of Medicine, Zanjan University of Medical Sciences, Zanjan, Iran; ${ }^{3}$ Proteomics Research Center, Faculty of Paramedical Sciences, Shahid Beheshti University of Medical Sciences, Tehran, Iran; ${ }^{4}$ Department of Clinical Biochemistry, Faculty of Medicine, Tehran University of Medical Sciences, Tehran, Iran; ${ }^{5}$ Department of Pathobiology and Laboratory Sciences, School of Medicine, North Khorasan University of Medical Sciences, Bojnurd, Iran

\section{Article Info:}

Keywords:

Soy isoflavones,

Soy food,

Adiponectin,

Postmenopausal women,

Meta-analysis.

Timeline:

Received: November 11, 2021

Accepted: December 27, 2021

Published: December 29, 2021

Citation: Tutunchi S, Koushki M, AmiriDashatan N, Khodabandehloo H, Hosseini H, Panahi G, Hashemi J, Karbalaee-Hasani A, Majidi Z, RezaeiTavirani M. Effect of Soy Isoflavones Supplementation on Adiponectin Levels in Postmenopausal Women: A MetaAnalysis. J Pharm Nutr Sci 2021; 11(1): 184-195.

DOI: https://doi.org/10.29169/1927-5951.2021.11.21

\begin{abstract}
:
Decreased adiponectin levels has been demonstrated in postmenopausal (PMP) women. Soy isoflavones, as an herbal product have been shown to increase adiponectin level but the results are inconclusive and inconsistent. The present study reassessed the data on the impact of soy isoflavones supplementation on adiponectin levels in PMP women through a meta-analysis. A systematic search was performed in the databases of PubMed, Web of science, Scopus and the Cochrane library. The literature search identified 830 studies with duplicates. Out of those, 80 were screened for title and abstract and 12 articles were ultimately selected for the analysis. Meta-regression and subgroup analyses, based on the moderator variables such as treatment duration, dose of soy isoflavones and BMI were performed. The quality of the studies was evaluated using the Grading of Recommendation Assessment, Development and Evaluation (GRADE) approach. The results revealed that soy isoflavones supplementation significantly increased the circulating level of adiponectin in PMP women (SMD: $0.36 \mu \mathrm{g} / \mathrm{mL} ; 95 \% \mathrm{Cl}(0.05$ to 0.66$) ; P=0.02)$. No publication bias was observed using Begg's $(P=0.38)$ and Egger's $(P=0.07)$ tests. Sensitivity analysis indicated the results were completely powerful and stable. Moreover, Meta-regression and subgroup analyses indicated a significant increase of adiponectin levels in subgroups of dose $>50 \mathrm{mg}$ and treatment duration less or equal 3 months. Our findings showed significantly increase in adiponectin levels after isoflavones-supplemented soy consumption in postmenopausal women, who received dose $>50 \mathrm{mg}$ of soy isoflavones in treatment duration $\leq 3$ months.
\end{abstract}

*Corresponding Author

Tel: +98-021-22714248

E-mail: tavirany@yahoo.com

(C) 2021 Tutunchi et al.; Licensee SET Publisher.

This is an open access article licensed under the terms of the Creative Commons Attribution Non-Commercial License (http://creativecommons.org/licenses/by-nc/3.0/) which permits unrestricted, non-commercial use, distribution and reproduction in any medium, provided the work is properly cited. 


\section{INTRODUCTION}

Menopause is a natural period in a woman's life when fertility ends because of the deprivation of ovarian function. Menopause usually started in women in the last $40 \mathrm{~s}$ to early $50 \mathrm{~s}[1,2]$. One of the important complications in postmenopausal women is an undesirable weight gain which increases the risk of obesity during postmenopause. Postmenopausalinduced obesity occurs due to physiological factors such as ageing, lifestyle factors including less physical activity and sedentary lifestyle, and psychological factors such as depression and stress [3, 4]. Obesity in postmenopausal women causes alterations in various metabolic risk factors associated with dyslipidemia, hypertension and insulin resistance. These risk factors include elevated abdominal fat, decreased insulin sensitivity and changes in circulating concentrations of adipokines such as adiponectin [5].

Adiponectin, as a fat-derived hormone, is functionally regulated by nutritional conditions and plays a key role in the regulation of energy equilibrium and metabolism [6]. In addition, adiponectin levels are negatively correlated with overall obesity parameters. Adiponectin is one of the adipocyte-produced hormones which is regulated by insulin resistance conditions and it is actively correlated with basal insulin concentrations and insulin sensitivity [7]. A low level of adiponectin has been shown to be correlated with elevated prevalence of metabolic syndrome, type 2 diabetes (T2D) and cardiovascular disease (CVD), especially in postmenopausal women $[7,8]$.

Nowadays, herbal products have been attracted much attention owing to their essential compounds and the wide range of biological roles and therapeutic impacts on various diseases [9] such as inflammatory-related diseases [10, 11], gastrointestinal diseases [12] and other diseases. According to the literature, increasing the level of adiponectin can be an effective strategy in reducing menopause-related complications in women. In this regard, natural products have been documented in increasing adiponectin levels in postmenopausal women. Soy, which has been commonly used in Asia for many years, has become a suitable candidate for its potential benefits in different populations such as postmenopausal women, T2D and breast cancer [13]. Furthermore, many trials demonstrated the protective effects of soy isoflavones on lipid metabolism, hypertension and vascular endothelial function [14]. In addition, soybean isoflavones have been shown to ameliorate metabolic disorders in postmenopausal women $[15,16]$. However, the effect of soy isoflavones on adipocytokines, particularly adiponectin in postmenopausal women remains unclear. Therefore, the objective of this study was to evaluate the effect of soybean isoflavones on circulation concentrations of adiponectin in postmenopausal women.

\section{MATERIALS AND METHODS}

\section{Search Strategy}

The protocol of this meta-analysis was performed based on the guidelines of the 2009 Preferred Reporting Items for Systematic Reviews and MetaAnalysis (PRISMA) statement [17]. An electronic search was performed using the databases of PubMed, Scopus, EMBASE, Web of Science, and Cochrane library to find RCTs evaluating the effect of soybean isoflavones on circulation level of adiponectin in postmenopausal women. The search was restricted to publication time and language. The Mesh database was applied using: ((soybean' [supplementary concept] OR "Soy supplementation [Title/Abstract]" OR "Soy isoflavones" OR "Soy protein") AND ("Adiponectin" [Mesh terms] OR "Adipose tissue adipokine" [Title/Abstract] OR "circulating white adipose tissue adipokine" [Title/abstract] AND "postmenopausal women" OR "Climacteric" OR "Menopause" OR "Menstruation")). Moreover, gray articles, conference presentations, reference lists and student dissertations were mutually searched to select further relevant studies.

\section{Principle of Studies Selection}

RCT studies were included if they covered the following criteria: 1) RCTs with or without consumption of other supplements, 2) articles with the English language, 3) articles with the association between the consumption of purified soy isoflavones and the alteration of the circulating level of adiponectin 4) articles with the sufficient data presentation such as standard deviations (SDs), standard error (SE), or 95\% confidence interval for adiponectin levels at the baseline and the end of the study in both intervention and placebo groups, 5) parallel or cross-over designs, and 6) articles with an appropriate RCT design. The following studies were excluded: 1) non-RCT studies, 2) studies without control or placebo groups, 3) lack of sufficient data on the concentration of adiponectin levels at the baseline or at the end of the follow-up period, and 4) lack of details in methodology. 


\section{Extraction of Primary Data and Quality Appraisal}

Extraction of data was conducted using a standardized electronic form by two expert researchers in this field. The extracted data are as follows: 1) first author's name; 2) origin country; 3) publication year; 4) dose of soy isoflavones $(\mathrm{mg})$; 5) duration of treatment (months); 6) postmenopausal women participants; 7) type of sample; 8) sample size of participants in the intervention and placebo groups; 9) mean $\pm S D$ of (serum/plasma) circulating level of adiponectin in both of treatment and placebo groups at the first and end of study (Table 1). A comprehensive assessment of the risk of bias was performed using the Jadad checklist [18]. The options used for the quality assessment of each study were as follows: 1) randomization, 2) double-blinding, 3) the number of participant dropouts and reasons for withdrawal, 4) allocation concealment and 5) generation of random numbers. Studies with a JADAD score greater than or equal to three were considered moderate to high quality.

\section{Quality of the Studies Based on GRADE Approach}

The quality of the studies for the primary outcome was assessed using the GRADE approach as proposed by the Cochrane Handbook for Systematic Reviews of Interventions [19]. The quality of the studies was estimated based on five parameters: 1) limitation of study design, 2) consistency of the results, 3)

Table 1: Baseline Characteristics of Included Studies Investigating the Impact of Soy Isoflavones on the Circulating Levels of Adiponectin in Postmenopausal Women

\begin{tabular}{|c|c|c|c|c|c|c|c|c|c|c|}
\hline \multirow{2}{*}{$\begin{array}{l}\text { Author's } \\
\text { name }\end{array}$} & \multirow[b]{2}{*}{ Country } & \multirow{2}{*}{$\begin{array}{c}\text { Sample } \\
\text { type }\end{array}$} & \multirow{2}{*}{$\begin{array}{l}\text { Dose } \\
\text { (mg) }\end{array}$} & \multirow{2}{*}{$\begin{array}{c}\text { Duration } \\
\text { (Month) }\end{array}$} & \multirow{2}{*}{$\begin{array}{c}\text { Type of } \\
\text { supplement }\end{array}$} & \multicolumn{2}{|c|}{ Case } & \multicolumn{2}{|c|}{ Placebo } & \multirow{2}{*}{$\begin{array}{l}\text { Jadac } \\
\text { score }\end{array}$} \\
\hline & & & & & & $\begin{array}{c}\text { Sample } \\
\text { Size }\end{array}$ & $\begin{array}{c}\text { Mean } \\
{[S D]}\end{array}$ & $\begin{array}{c}\text { Sample } \\
\text { Size }\end{array}$ & $\begin{array}{c}\text { Mean } \\
{[S D]}\end{array}$ & \\
\hline $\begin{array}{c}\text { Rebholz } \\
\text { et al. (2013) }\end{array}$ & USA & Serum & 89.3 & 2 & Powder & 32 & $\begin{array}{c}3.33 \\
{[0.36]}\end{array}$ & 35 & $\begin{array}{c}2.83 \\
{[0.35]}\end{array}$ & 5 \\
\hline $\begin{array}{c}\text { Charles } \\
\text { et al. (2009) }\end{array}$ & USA & Serum & 160 & 3 & Powder & 32 & $\begin{array}{c}20.6 \\
{[1.54]}\end{array}$ & 43 & $\begin{array}{r}19.5 \\
{[1.26]}\end{array}$ & 4 \\
\hline $\begin{array}{c}\text { Christie } \\
\text { et al. (2010) }\end{array}$ & UK & Serum & 160 & 3 & $\begin{array}{l}\text { Soy-based } \\
\text { shake }\end{array}$ & 17 & $\begin{array}{c}23.36 \\
{[3.6]}\end{array}$ & 16 & $\begin{array}{c}30.56 \\
{[5.5]}\end{array}$ & 5 \\
\hline $\begin{array}{c}\text { Llaneza } \\
\text { et al. (2011) }\end{array}$ & Spain & Serum & 80 & 12 & Extract & 43 & $\begin{array}{c}57.1 \\
{[59.1]}\end{array}$ & 44 & $\begin{array}{c}43.2 \\
{[32.2]}\end{array}$ & 3 \\
\hline $\begin{array}{c}\text { D'Anna } \\
\text { et al. (2014a) }\end{array}$ & Italy & Serum & 80 & 6 & Powder & 30 & $\begin{array}{l}17 \\
{[4]}\end{array}$ & 30 & $\begin{array}{l}16 \\
{[7]}\end{array}$ & 3 \\
\hline $\begin{array}{c}\text { D'Anna } \\
\text { et al. (2014b) }\end{array}$ & Italy & Serum & 80 & 12 & Powder & 30 & $\begin{array}{l}19 \\
{[5]}\end{array}$ & 30 & $\begin{array}{l}12 \\
{[6]}\end{array}$ & 3 \\
\hline $\begin{array}{c}\text { Matvienko } \\
\text { et al. (2010a) }\end{array}$ & USA & Serum & 80 & 6 & Tablet & 229 & $\begin{array}{l}17.3 \\
{[5.7]}\end{array}$ & 229 & $\begin{array}{l}17.5 \\
{[5.7]}\end{array}$ & 5 \\
\hline $\begin{array}{c}\text { Matvienko } \\
\text { et al. (2010b) }\end{array}$ & USA & Serum & 120 & 12 & Tablet & 229 & $\begin{array}{l}17.2 \\
{[5.7]}\end{array}$ & 229 & $\begin{array}{l}17.5 \\
{[5.7]}\end{array}$ & 5 \\
\hline $\begin{array}{c}\text { Riesco } \\
\text { et al. (2011) }\end{array}$ & Canada & Plasma & 70 & 6 & Capsule & 27 & $\begin{array}{c}19 \\
{[7.02]}\end{array}$ & 28 & $\begin{array}{c}20 \\
{[7.2]}\end{array}$ & 5 \\
\hline $\begin{array}{c}\text { Nadadur } \\
\text { et al. (2016) }\end{array}$ & USA & Serum & 50 & 2 & Soy-based diet & 17 & $\begin{array}{c}5.49 \\
{[0.42]}\end{array}$ & 20 & $\begin{array}{c}6.34 \\
{[0.45]}\end{array}$ & 5 \\
\hline $\begin{array}{c}\text { Maskarinec et } \\
\text { al. (2009) }\end{array}$ & USA & Serum & 50 & 24 & Soy-based diet & 83 & $\begin{array}{c}7.9 \\
{[3.9]}\end{array}$ & 85 & $\begin{array}{c}8.4 \\
{[3.9]}\end{array}$ & 3 \\
\hline $\begin{array}{c}\text { Llanos } \\
\text { et al. (2014) }\end{array}$ & USA & Serum & 60 & 2.5 & Soy based-diet & 60 & $\begin{array}{c}13.04 \\
{[1]}\end{array}$ & 60 & $\begin{array}{r}14.38 \\
{[1.02]}\end{array}$ & 3 \\
\hline $\begin{array}{c}\text { Simao } \\
\text { et al. (2012) }\end{array}$ & Brazil & Serum & 50 & 3 & Soy based-diet & 15 & $\begin{array}{c}115.3 \\
{[22.06]}\end{array}$ & 15 & $\begin{array}{c}112.6 \\
{[19.67]}\end{array}$ & 4 \\
\hline $\begin{array}{c}\text { Maskarinec et } \\
\text { al. (2017) }\end{array}$ & USA & Serum & 50 & 24 & Soy based-diet & 109 & $\begin{array}{c}7.9 \\
{[0.14]}\end{array}$ & 111 & $\begin{array}{c}8.4 \\
{[0.63]}\end{array}$ & 4 \\
\hline
\end{tabular}


directness, 4) precision and 5) publication bias. The GRADE score is classified as 'high', 'moderate', 'low', and 'very low' for the primary outcome.

\section{Statistical Analyses}

We analyzed the results qualitatively and quantitatively. The collected data were combined using randomeffects models. The circulating level of adiponectin under the consumption of soy isoflavones is the main primary outcome. Weighted averages were presented as SMD (Cohen's d) with 95\% confidence intervals $\left(\mathrm{Cl}_{S}\right)$. If the circulating level of adiponectin was reported in the median and interquartile range (IQR), mean and standard deviations (SD) values were calculated using a method previously defined [20]. Tests were analyzed as the difference in mean between control and treatment groups. In addition, SD of mean difference was calculated by pooled SD; SDs of the mean difference were calculated using the following formula: $\mathrm{SD}=$ square root $\left[(\text { SD pre-treatment })^{2}+\right.$ (SD post- $^{2}$ treatment $^{2}-(2 \mathrm{R} \times$ SDpre-treatment $\times \mathrm{SD}$ posttreatment)], assuming a correlation coefficient $(R)=$ 0.5. In the case of reporting SEM, SD was calculated using the following formula: $S D=\operatorname{SEM} \times$ sqrt $(n)$, where $n$ is the number of subjects. The following formula was also applied for examination of pooled mean and pooled SD at the first and end of the study in both of the treatment and control groups. The statistically inter-study heterogeneity was estimated using the Cochrane index and the Higgins I-square. $P$ $<0.1$ and $\mathrm{I}^{2}>50 \%$ accepted as obvious heterogeneity. To find out the source of heterogeneity among the studies, subgroup analyses were conducted based on the duration of the intervention ( $\leq 3$ and $>3$ months), the dose of soy isoflavones ( $\leq 50$ and $>50 \mathrm{mg} /$ day) and body mass index (BMI) $(<30,>30)$. The Begg's rank correlation test and the Egger's regression asymmetry test were used to assess the possible publication bias [21, 22]. A sensitivity test was also performed to evaluate the consequence of the removal of the study with a larger sample size on the overall effect size using the "leave-one-out method". Metaregression was analyzed based on restricted maximum likelihood-based random effects for evaluation of the effect of the variables of duration, a dose of consumption of soy isoflavones and BMI on estimated pooled effect size. A $P$-value threshold of 0.05 was applied to determine the statistical significance. Statistical analyses for all tests were performed using the Comprehensive Meta-Analysis (CMA) V2 software (Biostat, NJ) [23].

\section{RESULTS}

\section{Process of Studies Search}

Our literature search identified collectively 830 articles in four databases. Following the screening of titles, abstracts and full text we rejected 750 duplicates. The remaining articles were further reviewed. Sixty-six articles were removed due to the following reasons: no or insufficient information, lack of English language, articles that were review paper or editorial letter, articles that have not reported the circulating level of adiponectin as a primary outcome, and articles with animal and in vitro study subjects. Moreover, articles were also excluded due to the unavailability of their full texts. Lastly, 12 articles were included based on the designed question in the study. Details of the study selection are summarized in Figure 1.

\section{Primary Characteristics of Included Studies}

In total, 12 RCTs published have reported the differences in circulating adiponectin concentrations as a primary outcome after consumption of soy isoflavones. Table 1 lists the studies used in the present meta-analysis. The mean oral dose of soy isoflavones was $87.7 \mathrm{mg} /$ day (ranged between 50 to $160 \mathrm{mg} /$ day). The average age for treatment and control groups ranged between 48-60 years. In all trials, the circulating level of adiponectin in the intervention group was compared to the placebo group. The time of follow-up of consumption of soy isoflavones ranged from two months to 24 months. A total of 953 subjects in the treatment group and 975 subjects in the control group participated in this study. Finally, of the 12 RCTs, six trials used soy food diet, one study used soy isoflavones extract, two trials used soy tablets or capsules and three studies used soy powder dissolved in liquid. In all of these studies, isoflavones was an active ingredient. Serum samples were used in nine studies and three studies used plasma samples. Italy $(n=2)$, Canada $(n=1)$, Spain $(n=1)$, Brazil $(n=1)$ and USA $(n=7)$ were the countries that handled the studies. All of the eligible studies in this meta-analysis used placebo as a control. The quality assessment of the studies is shown in Table 1. The JADAD-based quality of the eligible studies was moderate to high, while the GRADE method indicated that the quality of the studies for the primary result was high. The significant inter-study heterogeneity of studies has been shown in Table 2. 

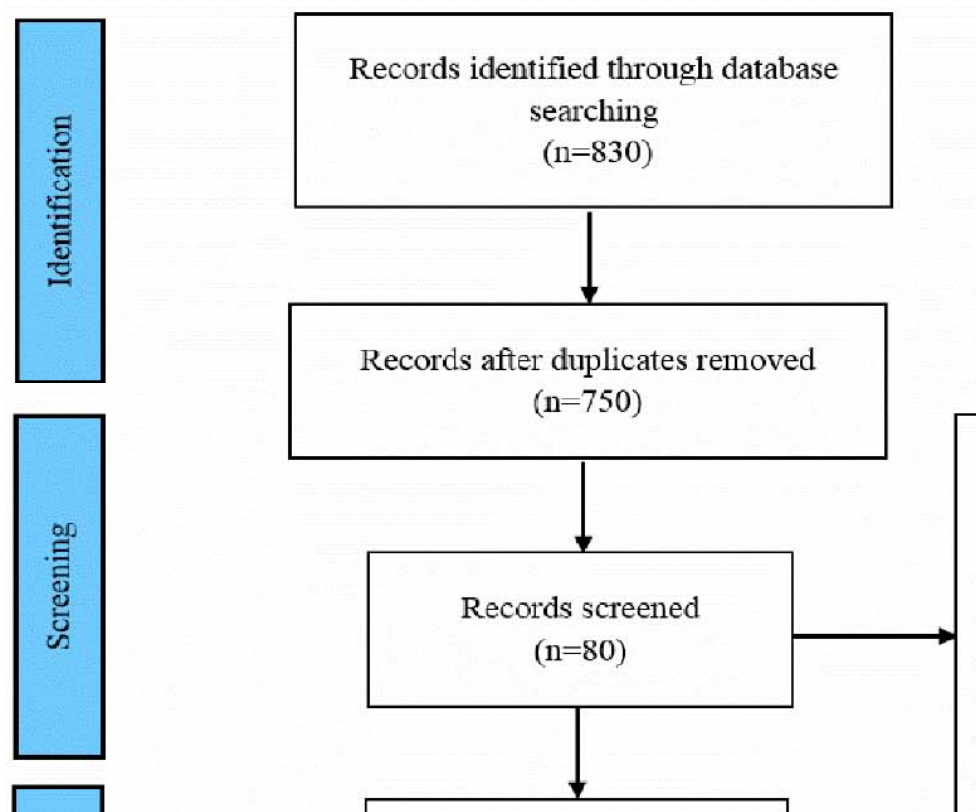

Records excluded, with reasons: $(\mathrm{n}=66)$

-Observational studies

-Letters/conference abstract

-Review/ brief report

-Insufficient data

-Not English language

- Unavailability to their full-text



Full-text articles assessed for eligibility $(\mathrm{n}=14)$

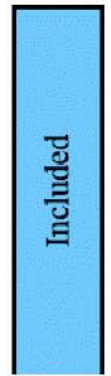

Studies included in quantitative synthesis $(\mathrm{n}=12)$

Full-text articles excluded, With reasons: $(\mathrm{n}=2)$

-women with other disease

Studies included in quantitative synthesis $(\mathrm{n}=12)$

Figure 1: The process of study selection is based on PRISMA guideline.

Table 2: Evaluation the Quality Level of Evidences using the GRADE Approach.

\begin{tabular}{|c|c|c|c|c|c|c|c|}
\hline $\begin{array}{l}\text { Quality } \\
\text { status }\end{array}$ & $\begin{array}{l}\text { Effect size } \\
\qquad(\mathrm{Cl} \%)\end{array}$ & Imprecision $^{* * * *}$ & Indirectness ${ }^{* * *}$ & Inconsistency $^{* *}$ & Limitations $^{*}$ & $\begin{array}{l}\text { Studies } \\
\text { Number }\end{array}$ & $\begin{array}{l}\text { Primary } \\
\text { outcome }\end{array}$ \\
\hline High & $\begin{array}{c}0.029 \\
(-0.33,0.39)\end{array}$ & No serious & No serious & Serious & No serious & 12 & $\begin{array}{c}\text { Adiponectin } \\
(\mu \mathrm{g} / \mathrm{ml})\end{array}$ \\
\hline
\end{tabular}

* = Limitation in study design (absence of allocation concealment, absence of blinding, miss of follow up and so on).

${ }^{* *}=$ Inconsistency (high heterogeneity).

*** = Indirectness (the evidence is restricted to indirect comparisons between two interventions).

$* * * *=$ Imprecision (wide confidence interval).

\section{Soy Isoflavones Supplementation and Circulating Level of Adiponectin}

Figure 2 show the SMD and $95 \% \mathrm{Cl}$ for the impact of soy isoflavones on adiponectin levels in postmenopausal women in comparison to control.
There was significant heterogeneity among included studies $(I 2=89.7 \%$, PHeterogenity $<0.001)$. Therefore, the random-effects model was used to estimate the pooled SMD and $95 \% \mathrm{Cl}$ for the primary outcome. The meta-analysis revealed significantly higher levels of 


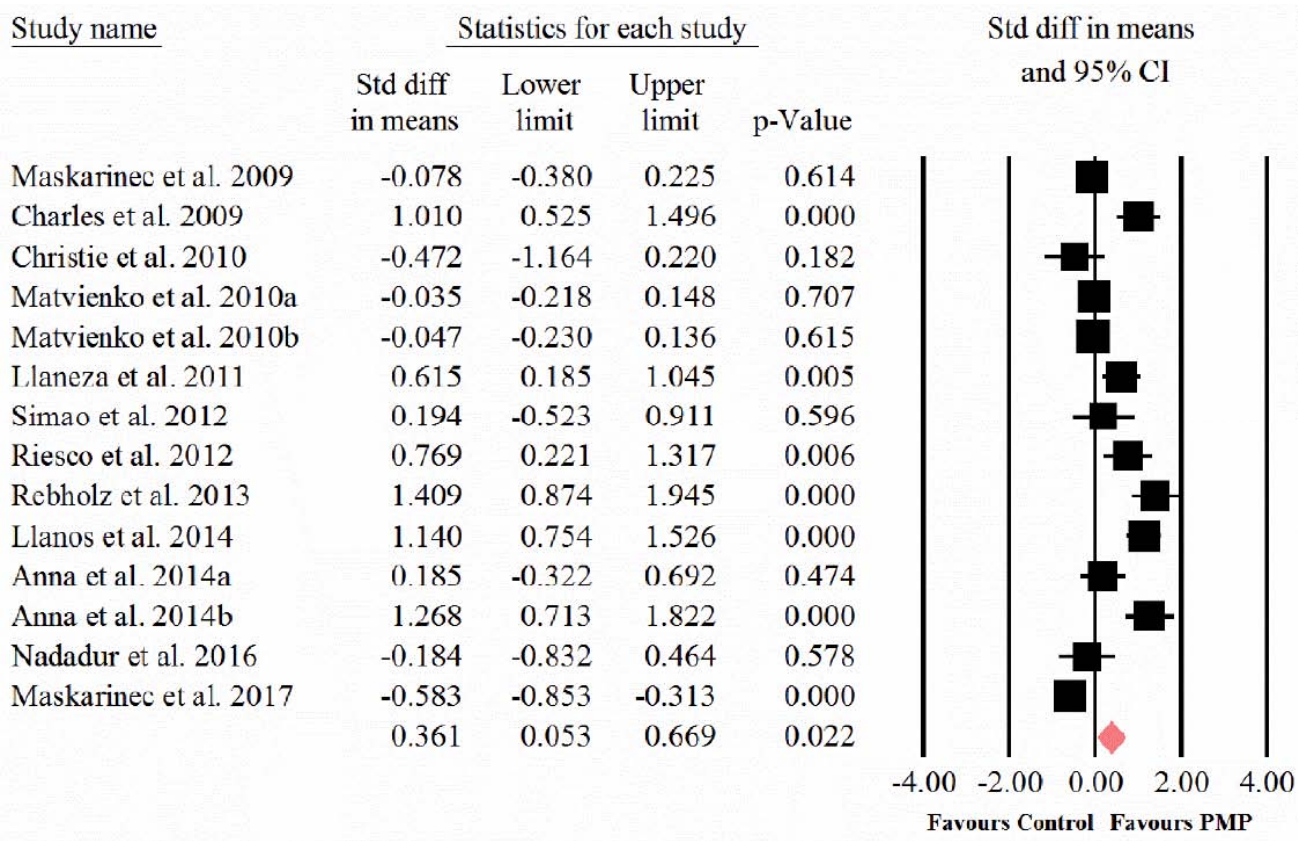

Figure 2: Forest plot detailing standardized mean difference (SMD) and $95 \%$ confidence intervals for the effect of soy isoflavones on circulating adiponectin level in postmenopausal women.

adiponectin in PMP in comparison to healthy control after soy isoflavones consumption (SMD: $0.36 \mu \mathrm{g} / \mathrm{mL}$; $95 \% \mathrm{Cl}(0.05$ to 0.66$) ; \mathrm{P}=0.022)$.

\section{Sensitivity Analysis}

Sensitivity analysis was conducted using the "leaveone-out" method. Interestingly, Sensitivity analysis showed no significant change in the pooled effect size by removing each study step by step. Moreover, the exclusion of the Matvienko study with a larger sample size did not change the estimated pooled analysis for circulating level of adiponectin [SMD: $0.39 \mu \mathrm{g} / \mathrm{mL}$; $95 \%$ $\mathrm{Cl}(0.038$ to 0.75$) ; P=0.030]$. Thus, the outcome of this pooled effect size could be considered with a high degree of certainty.

\section{Publication Bias}

Begg's rank correlation and Egger's linear regression tests were performed to evaluate publication bias. Visual examination of the funnel plot did not show potential publication bias (Figure 3 ). In addition, the Begg's rank correlation (Kendall"s Tau with continuity correction $=0.11, Z=0.54$, two-tailed $P$-value $=0.58)$ and the Egger's linear regression tests (intercept $=3.4$, standard error $=1.65 ; 95 \% \mathrm{Cl}=-0.17,7.03, \mathrm{t}=2.07, \mathrm{df}$ $=12$, two-tailed $P=0.06$ ) were not significant. The

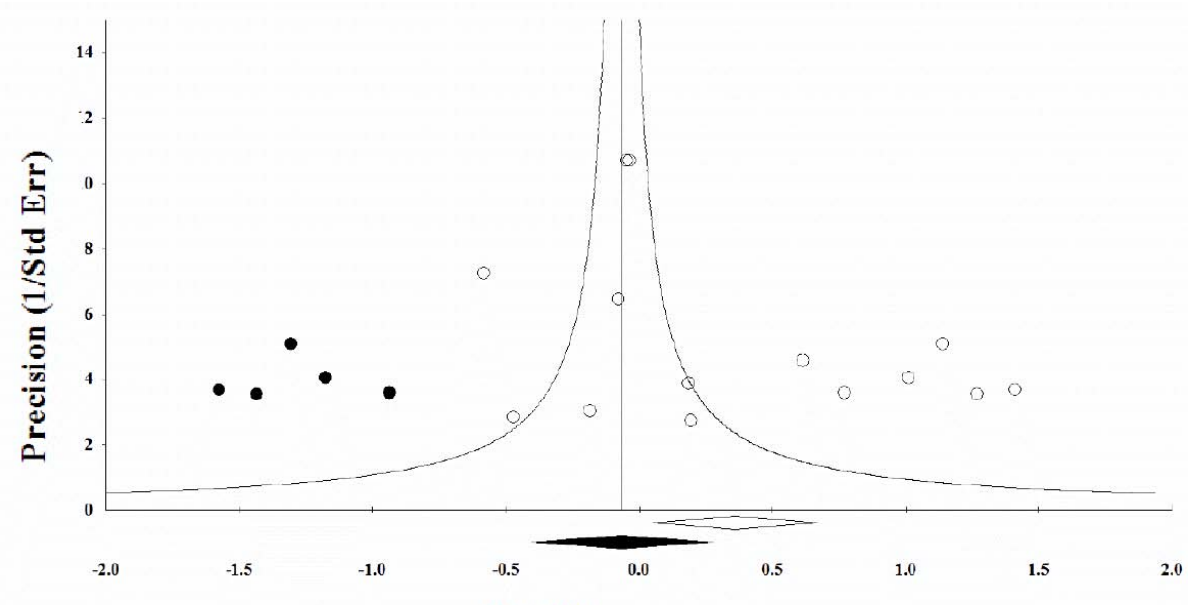

Std diff in means

Figure 3: Funnel plot examining publication bias in the studies including the effect of soy isoflavones on circulating adiponectin level in postmenopausal women after trimming and filling. 
observed publication bias was imputed using trim-andfill correction. Five potentially missing studies were imputed leading to a corrected pooled effect size that was less than the first estimate (SMD: $-0.06 ; 95 \% \mathrm{Cl}-$ $0.40,0.27)$.

\section{Meta-Regression and Subgroup Analyses}

Meta-regression analysis indicated no significant correlation between dose (mg) (slope: 0.0005;
95\% Cl: $-0.008,0.009 ; \mathrm{p}=0.90$ ) and BMI (slope: $0.020 ; 95 \% \mathrm{Cl}:-0.019,0.060 ; p=0.31$ ) with the impact of soy isoflavones on circulating levels of adiponectin in PMP. However, an inverse association with treatment duration (slope: - 0.040; 95\% Cl: $-0.077,-0.003 ; p=$ 0.030) was found (Figure 4). On the other hand, to find out the source of between-study heterogeneity, subgroup analyses were conducted according to the known confounding factors such as dose $(\leq 50$ and $>50$
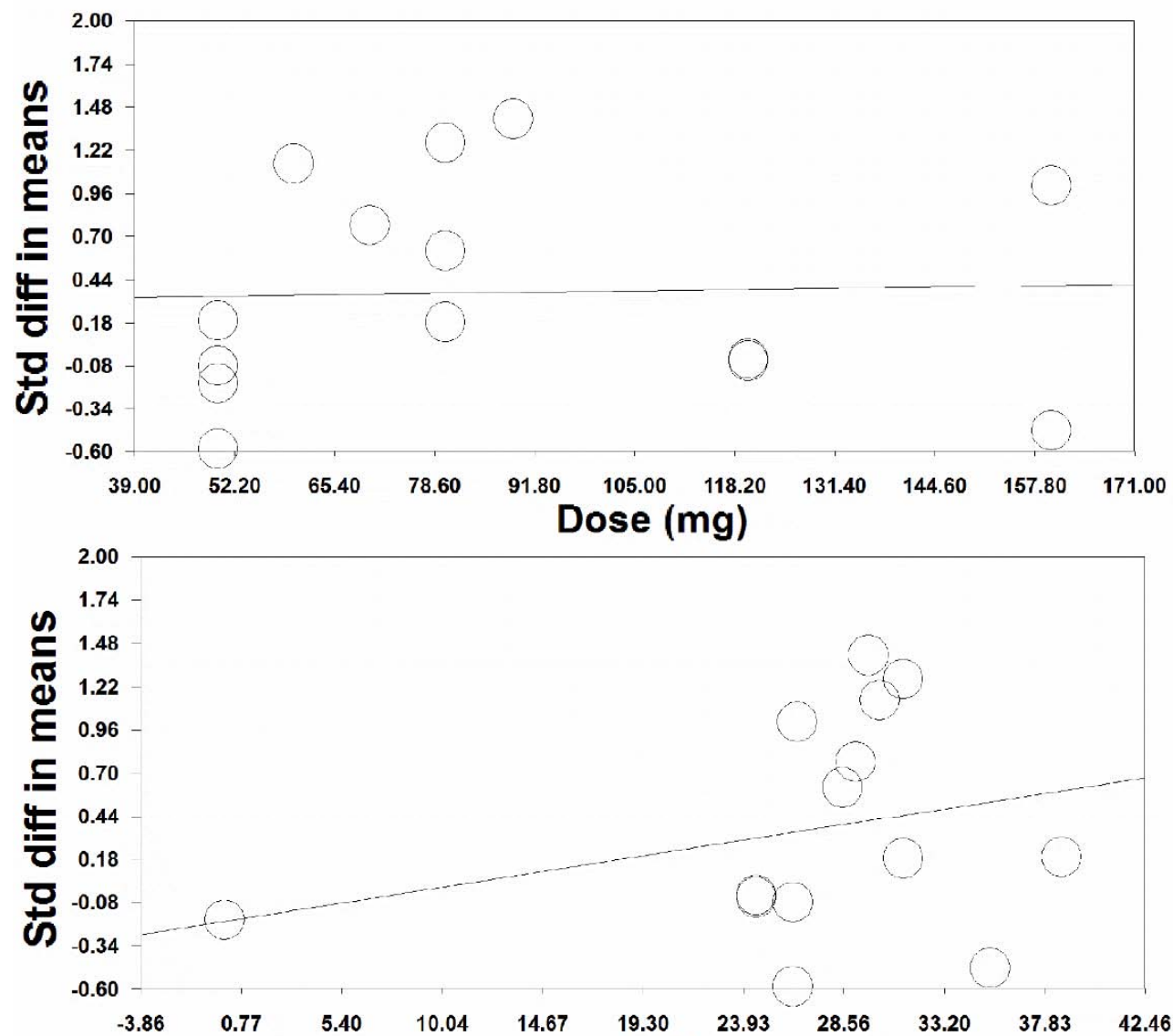

BMI

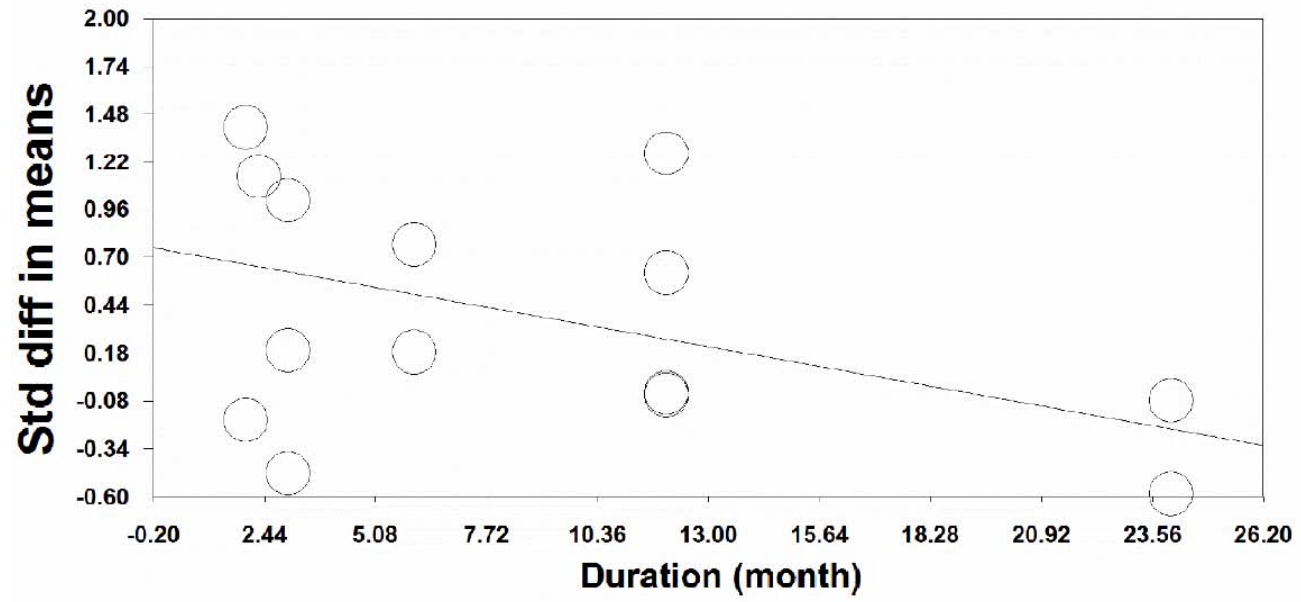

Figure 4: Meta-regression plots of the association between the circulating adiponectin levels of in postmenopausal women with treatment duration, dose of soy isoflavones and BMI. 
Table 3: Assessment of the Impact of Soy Isoflavones on Circulating Adiponectin Level using Subgroup Analyses

\begin{tabular}{|c|c|c|c|c|c|}
\hline \multirow{2}{*}{ Subgroup } & \multirow{2}{*}{ Number of RCTs } & \multirow{2}{*}{ SMD (95\% CI) } & \multirow{2}{*}{$p$} & \multicolumn{2}{|c|}{ Test of Heterogeneity } \\
\hline & & & & $I^{2}(\%)$ & $P$ \\
\hline Adiponectin $(\mu \mathrm{g} / \mathrm{mL})$ & 12 & $0.36(0.05,0.66)$ & 0.022 & 89.7 & $<0.001$ \\
\hline \multicolumn{6}{|l|}{ Dose (mg/ day) } \\
\hline$\leq 50$ & 4 & $-0.22(-0.58,0.12)$ & 0.20 & 63.5 & 0.04 \\
\hline$>50$ & 8 & $0.57(0.20,0.94)$ & 0.002 & 90 & $<0.001$ \\
\hline \multicolumn{6}{|l|}{ Duration (months) } \\
\hline$\leq 3$ & 6 & $0.55(-0.02,1.13)$ & 0.04 & 84.8 & $<0.001$ \\
\hline$>3$ & 6 & $0.20(-0.10,0.50)$ & 0.20 & 87.1 & $<0.001$ \\
\hline \multicolumn{6}{|l|}{ BMI } \\
\hline Unmatch & 4 & $0.36(-0.15,0.87)$ & 0.17 & 83.8 & $<0.001$ \\
\hline match & 8 & $0.36(-0.04,0.77)$ & 0.08 & 92.3 & $<0.001$ \\
\hline
\end{tabular}

$\mathrm{mg} / \mathrm{day}$ ), BMI and treatment duration. We found that the impact of soy isoflavones was significantly associated with a dose higher than $50 \mathrm{mg}$ in comparison to a dose less than $50 \mathrm{mg}$. So that, this significant effect was also seen in treatment duration less or equal to 3 months (Table 3 ).

\section{DISCUSSION}

The early stage of a postmenopausal period is related to an increase in abdominal fat and central obesity. Increased adiposity, especially visceral fat accumulation, following obesity is related to metabolic dysfunctions such as insulin resistance, dyslipidemia and hypertension [24]. Adipose tissue produces and releases hormones that regulate several metabolic activities of the human body [25]. Adiponectin is an adipokine is a hormone that has a protective role against obesity-related disorders such as T2D and CVD [24]. Adiponectin plays an important role in various metabolic pathways such as fatty acid oxidation in muscle, improving insulin sensitivity in the liver and glucose utilization [26]. Furthermore, previous studies have reported that adiponectin directly or indirectly affects insulin sensitivity and glucose and lipid profiles [27]. The most recent work by Stork et al. indicated that alteration in carotid intima-media thickness and stiffness was associated with the decreased adiponectin concentration in postmenopausal women [28]. It should be noted that the circulating level of adiponectin is dependent on the circulating concentrations of inflammatory mediators such as IL-6 and TNF- $\alpha$ [29]. Moreover, decreased concentration of adiponectin leads to an increased risk of inflammatory and metabolic disorders [30]. Published studies revealed that the circulating level of adiponectin in obese women is obviously lower than in non-obese postmenopausal women. Therefore, weight gain and obesity are two important signs of the progression of metabolic syndrome in postmenopausal women [31]. Nevertheless, at the postmenopausal age, low adiponectin level is related to the obesity-related metabolic syndrome in the liver and muscle tissues [32].

With respect to the potential role of adiponectin in insulin resistance, atherogenesis and obesity in postmenopausal women, in this meta-analysis, our research focused on the effect of soy isoflavones on the circulating level of adiponectin in postmenopausal women. Our analysis showed a statistically significant increase in adiponectin level after consumption of soy isoflavones. In contrast with our result, some studies reported no statistically significant difference in circulating level of adiponectin compared to the control group (Charles et al., 2009; Christie et al., 2010; Llanos et al., 2014, Nadadur, Stanczyk, Tseng, Kim, \& Wu, 2016). In line with our study, there is published documents showing the favourable effect of soy isoflavones on the circulating level of adiponectin in postmenopausal women [33-37]. However, what should be taken into consideration is that the dose of intervention, time of menopause, treatment duration, as well as BMI of participating women could affect the results. Although we expected to discover a considerable effect of soy supplementation on the circulating level of adiponectin, it was statistically significant. This may be because of the homogeneity characteristics of postmenopausal women who 
participated in the included studies. Thus, we enhanced statistical power by using subgroup analyses and meta-regression to estimate the effect of intervention.

Postmenopause is associated with changes in several metabolic risk factors including decreased adiponectin and increased circulating inflammatory mediators such as TNF-a and IL-6 $[38,39]$. With respect to the inconsistent results on adiponectin levels under soy isoflavones in postmenopausal women. As, adiponectin levels increased significantly in some studies [34, 40], while, no increase in adiponectin levels was observed with soy isoflavones in two studies [5, 41].

The precise molecular mechanism of adiponectinincreasing of soy isoflavones is not clear. It is possible that the increasing effect of soy isoflavones on adiponectin levels in postmenopausal women depends on the abdominal fat, glucose and insulin metabolism [5]. Thus, the change in glucose homeostasis and insulin pathway is a pioneer in decreasing adiponectin levels in postmenopausal women. In this regard, Jayagopal et al., have shown that consumption of soy isoflavones improves insulin resistance and $\mathrm{HbA} 1 \mathrm{c}$ in postmenopausal women with type 2 diabetes [42]. The other main mechanisms involved in decreasing adiponectin levels in postmenopausal women are inflammatory cytokines. Inflammatory mediators of TNF- $\alpha$ and IL- 6 are known to cause insulin resistance and decrease in circulating levels of adiponectin. These cytokines cause it by downregulating insulin receptor substrate (IRS-1) and by decreasing glucose transporting protein-1 (GLUT-1) [43]. Thus, a reduction in inflammatory markers could be effective in the rise of adiponectin levels in postmenopausal women. For this reason, studies have demonstrated a decrease in the TNF-a levels following treatment with soy isoflavones in postmenopausal women [44]. In addition, a study showed that soy supplement reduced IL- 6 though decrease in abdominal fat, since IL- 6 is produced by subcutaneous abdominal fat [45]. Also, soy isoflavones could downregulate IL-6 via its transcription factor nuclear factor $K_{\beta}\left(N F-K_{\beta}\right)$ [46]. The function of soy isoflavones through their anti-oxidant properties is well known in the prevention and treatment of various diseases. In this regard, a previous study reported that the impacts of soy isoflavones against UVB radiation may be related to the anti-oxidative activities [47]. On the other hand, Genistein is a soy isoflavone leading to restore the glutathione (GSH) level and decrease ROS and lipoperoxide levels in the brain and liver [48]. Taken together, we believe that the adiponectin- increasing role of soy isoflavones should be further explored in large prospective trials in menopause and postmenopausal women.

Our results showed significant heterogeneity among the studies. Therefore, to find the remarkable heterogeneity, subgroup analyses were conducted according to the dose of soy isoflavones ( $\leq 50$ and $>50$ $\mathrm{mg} /$ day), treatment duration ( $\leq 3$ and $>3$ weeks) and BMI (Unmatch and match). The results revealed that soy isoflavones significantly increased the circulating levels of adiponectin in PMP with dose $>50 \mathrm{mg}$ and treatment duration less or equal to 3 months. In addition, we found no significant association between $\mathrm{BMI}$ of the intervention group and the circulating levels of adiponectin following consumption of soy isoflavones. However, subgroup analyses findings were further confirmed by the meta-regression analysis. The meta-regression analysis showed that the dose of soy isoflavones and BMI have no significant effects on the circulating level of adiponectin, while, there was an inverse association between treatment duration and the impact of soy isoflavones on adiponectin levels in PMP. Taken tighter, these differences may be partly because of the small sample size of the intervention group, the significant heterogeneity among included studies and the type of soy isoflavones (food or supplement).

This study has several strengths: the literature search was comprehensive and covered multiple databases. Statistical analysis revealed no considerable publication bias within studies. A precise assessment of the methodological quality of eligible studies using JADAD scale acknowledged that RCTs quality was moderate to high. We performed subgroup analyses to find out the possible source of heterogeneity. All of the included studies have used purified soy supplementation (isoflavones and proteins). Our metaanalysis also had several limitations: due to the relatively low number of articles in pooled effect size and subgroup analyses, the results should be interpreted cautiously. Moreover, regarding the significant heterogeneity among included studies, more studies evaluating the effect of soy supplementation on the circulating level of adiponectin in postmenopausal period are needed to further validate the results of the present study.

\section{CONCLUSION}

The present meta-analysis evidences a significant increasing effect of soy isoflavones on the circulating 
levels of adiponectin in postmenopausal women. The dose of soy isoflavones and treatment duration may modify this effect toward to more significant. However, required further studies with larger sample sizes and appropriate intervention for dose and treatment duration to identify the precise relationship between soy isoflavones and adiponectin levels in postmenopausal women.

\section{ACKNOWLEDGEMENTS}

We would like to extend our gratitude to the proteomics research center, Shahid Beheshti University of Medical Sciences for their executive supports.

\section{FUNDING}

The authors received no specific funding or grant for this work.

\section{CONFLICT OF INTEREST}

The authors declare that they have no conflicts of interest.

\section{AVAILABILITY OF DATA AND MATERIALS}

All of data are presented within the article. Additional data or information can be requested by contacting the corresponding author.

\section{ETHICS APPROVAL STATEMENT}

Ethical approval and informed consent is not necessary for this study.

\section{PATIENT CONSENT STATEMENT}

Not applicable.

\section{AUTHORS' CONTRIBUTIONS}

ST, MK, NA. D, H Kh, HH and MR. T contributed to the design, concept, quality assessment strategy, and acquisition of data. The process of studies selection and evaluation of their eligibility and quality was performed by ST, MK, NA. D, GP, H Kh, AK.H and MR. T. All the authors participated in literature search. MK, NA. D and JH carry out the statistical analyses. All the authors contributed in writing the draft of manuscript. All the authors also read, provided critical revision, and approved the final manuscript.

\section{ABBREVIATIONS}

PMP = Postmenopausal

PRISMA = Preferred reporting items for systematic review and meta-analysis
RCT = Randomized controlled trials

SD = Standard deviations

$\mathrm{SE} \quad=$ Standard error

SMD = Standardized mean difference

IQR = Interquartile range

\section{REFERENCES}

[1] Faddy M, Gosden R. Ovary and ovulation: a model conforming the decline in follicle numbers to the age of menopause in women. Human Reproduction 1996;. 11(7): 1484-1486.

https://doi.org/10.1093/oxfordjournals.humrep.a019422

[2] McKinlay SM. The normal menopause transition: an overview. Maturitas 1996; 23(2): 137-45. https://doi.org/10.1016/0378-5122(95)00985-X

[3] Di Carlo C, et al. Serum leptin levels and body composition in postmenopausal women: effects of hormone therapy. Menopause 2004; 11(4): 466-73. https://doi.org/10.1097/01.GME.0000109313.11228.2B

[4] Jassi $\mathrm{H}$, et al. Effect of soy proteins vs soy isoflavones on lipid profile in postmenopausal women. Indian Journal of Clinical Biochemistry 2010; 25(2): 201-207. https://doi.org/10.1007/s12291-010-0036-8

[5] Christie DR, et al. Metabolic effects of soy supplementation in postmenopausal Caucasian and African American women: a randomized, placebo-controlled trial. American Journal of Obstetrics and Gynecology 2010; 203(2): 153. e1-153. e9. https://doi.org/10.1016/j.ajog.2010.02.058

[6] Silha JV, et al. Plasma resistin, adiponectin and leptin levels in lean and obese subjects: correlations with insulin resistance. European Journal of Endocrinology 2003; 149(4): 331-336. https://doi.org/10.1530/eje.0.1490331

[7] Hroussalas G, et al. Leptin, soluble leptin receptor, adiponectin and resistin in relation to OGTT in overweight/obese postmenopausal women. Maturitas 2008; 59(4): 339-349.

https://doi.org/10.1016/j.maturitas.2008.03.012

[8] Silha JV, et al. Plasma resistin, adiponectin and leptin levels in lean and obese subjects: correlations with insulin resistance. European Journal of Endocrinology 2003; 149(4): 331-335.

https://doi.org/10.1530/eje.0.1490331

[9] Koushki $\mathrm{M}$, et al. Resveratrol: $\mathrm{A}$ miraculous natural compound for diseases treatment. Food Science \& Nutrition 2018; 6(8): 2473-2490. https://doi.org/10.1002/fsn3.855

[10] Koushki M, Dashatan NA, Meshkani R. Effect of resveratrol supplementation on inflammatory markers: a systematic review and meta-analysis of randomized controlled trials. Clinical Therapeutics 2018; 40(7): 1180-1192. e5. https://doi.org/10.1016/j.clinthera.2018.05.015

[11] Koushki $M$, et al. Effect of garlic intake on inflammatory mediators: a systematic review and meta-analysis of randomised controlled trials. Postgraduate Medical Journal 2020.

https://doi.org/10.1136/postgradmedj-2019-137267

[12] Koushki $M$, et al. Therapeutic effects of hydro-alcoholic extract of Achillea wilhelmsii $C$. Koch on indomethacininduced gastric ulcer in rats: a proteomic and metabolomic 
approach. BMC Complementary and Alternative Medicine 2019; 19(1): 205.

https://doi.org/10.1186/s12906-019-2623-4

[13] Kwon DY, et al. Antidiabetic effects of fermented soybean products on type 2 diabetes. Nutrition Research 2010; 30(1): 1-13.

https://doi.org/10.1016/j.nutres.2009.11.004

[14] González S, et al. Effects of isoflavone dietary supplementation on cardiovascular risk factors in type 2 diabetes. Diabetes Care 2007; 30(7): 1871-1873. https://doi.org/10.2337/dc06-1814

[15] Brandi M. Natural and synthetic isoflavones in the prevention and treatment of chronic diseases. Calcified Tissue International 1997; 61(1): S5-S8. https://doi.org/10.1007/s002239900376

[16] Riesco E, et al. Effect of exercise training combined with phytoestrogens on adipokines and C-reactive protein in postmenopausal women: a randomized trial. Metabolism 2012; 61(2): 273-280.

https://doi.org/10.1016/j.metabol.2011.06.025

[17] Moher D, et al. Preferred reporting items for systematic reviews and meta-analyses: the PRISMA statement. PLoS Medicine 2009; 6(7): e1000097. https://doi.org/10.1371/journal.pmed.1000097

[18] Jadad AR, et al. Assessing the quality of reports of randomized clinical trials: Is blinding necessary? Controlled Clinical Trials 1996; 17(1): 1-12. https://doi.org/10.1016/0197-2456(95)00134-4

[19] Guyatt $\mathrm{GH}$, et al. GRADE: an emerging consensus on rating quality of evidence and strength of recommendations. BMJ 2008; 336(7650): 924-926. https://doi.org/10.1136/bmj.39489.470347.AD

[20] Hozo SP, Djulbegovic B, Hozo I. Estimating the mean and variance from the median, range, and the size of a sample. BMC Med Res Methodol 2005; 5: 13. https://doi.org/10.1186/1471-2288-5-13

[21] Begg CB, Mazumdar M. Operating characteristics of a rank correlation test for publication bias. Biometrics 1994; p. 10881101.

https://doi.org/10.2307/2533446

[22] Egger $\mathrm{M}$, et al. Bias in meta-analysis detected by a simple, graphical test. BMJ 1997; 315(7109): 629-634. https://doi.org/10.1136/bmj.315.7109.629

[23] Borenstein M, et al. Comprehensive meta-analysis version 2. Englewood, NJ: Biostat 2005; 104.

[24] Mankowska A, Nowak L, Sypniewska G. Adiponectin and Metabolic Syndrome in Women at Menopause. Ejifcc 2009; 19(4): 173-84.

[25] Koerner A, Kratzsch J, Kiess W. Adipocytokines: leptin--the classical, resistin--the controversical, adiponectin--the promising, and more to come. Best Pract Res Clin Endocrinol Metab 2005; 19(4): 525-46.

https://doi.org/10.1016/..beem.2005.07.008

[26] Karbowska J, Warczak E, Kochan Z. [Adiponectin gene polymorphism and protein dysfunction in the development of insulin resistance]. Postepy Hig Med Dosw (Online) 2004; 58: 449-57.

[27] Ryo $\mathrm{M}$, et al. Adiponectin as a biomarker of the metabolic syndrome. Circ J 2004; 68(11): 975-81. https://doi.org/10.1253/circj.68.975

[28] Stork S, et al. Low levels of adiponectin predict worsening of arterial morphology and function. Atherosclerosis 2007; 194(2): e147-53. https://doi.org/10.1016/j.atherosclerosis.2006.11.044

[29] Miyatani $Y$, et al. Associations of circulating adiponectin with estradiol and monocyte chemotactic protein-1 in postmenopausal women. Menopause 2008; 15(3): 536-41. https://doi.org/10.1097/gme.0b013e31815c85ed
[30] Engeli S, et al. Association between adiponectin and mediators of inflammation in obese women. Diabetes 2003; 52(4): 942-7.

https://doi.org/10.2337/diabetes.52.4.942

[31] Lobo RA, Metabolic syndrome after menopause and the role of hormones. Maturitas 2008; 60(1): 10-8. https://doi.org/10.1016/j.maturitas.2008.02.008

[32] Lu JY, et al. Adiponectin: a biomarker of obesity-induced insulin resistance in adipose tissue and beyond. J Biomed Sci 2008; 15(5): 565-76 https://doi.org/10.1007/s11373-008-9261-z

[33] D'Anna R, et al. Effects of a new flavonoid and Myo-inosito supplement on some biomarkers of cardiovascular risk in postmenopausal women: a randomized trial. International Journal of Endocrinology 2014; 2014. https://doi.org/10.1155/2014/653561

[34] Lozovoy MAB, et al. Blood pressure decrease with ingestion of a soya product (kinako) or fish oil in women with the metabolic syndrome: role of adiponectin and nitric oxide. British Journal of Nutrition 2012; 108(8): 1435-1442. https://doi.org/10.1017/S0007114511006921

[35] Llaneza $\mathrm{P}$, et al. Soy isoflavones, diet and physical exercise modify serum cytokines in healthy obese postmenopausal women. Phytomedicine 2011; 18(4): 245-50. https://doi.org/10.1016/j.phymed.2010.07.011

[36] Matvienko OA, et al. Appetitive hormones, but not isoflavone tablets, influence overall and central adiposity in healthy postmenopausal women. Menopause 2010; 17(3): 594-601. https://doi.org/10.1097/gme.0b013e3181c92134

[37] Maskarinec G, et al. Inflammatory markers in a 2-year soy intervention among premenopausal women. J Inflamm (Lond) 2009; 6: 9. https://doi.org/10.1186/1476-9255-6-9

[38] Wildman R, et al. Adipocytokine and ghrelin levels in relation to cardiovascular disease risk factors in women at midlife: longitudinal associations. International Journal of Obesity 2008; 32(5): 740-748. https://doi.org/10.1038/sj.ijo.0803782

[39] Sites CK, et al. Menopause-related differences in inflammation markers and their relationship to body fat distribution and insulin-stimulated glucose disposal. Fertility and Sterility 2002; 77(1): 128-135. https://doi.org/10.1016/S0015-0282(01)02934-X

[40] Llaneza $P$, et al. Soy isoflavones, diet and physical exercise modify serum cytokines in healthy obese postmenopausal women. Phytomedicine 2011; 18(4): 245-250. https://doi.org/10.1016/j.phymed.2010.07.011

[41] Maskarinec G, et al. Inflammatory markers in a 2-year soy intervention among premenopausal women. Journal of Inflammation 2009; 6(1): 1-7. https://doi.org/10.1186/1476-9255-6-9

[42] Jayagopal $V$, et al. Beneficial effects of soy phytoestrogen intake in postmenopausal women with type 2 diabetes. Diabetes Care 2002; 25(10): 1709-1714. https://doi.org/10.2337/diacare.25.10.1709

[43] Arner P. Insulin resistance in type 2 diabetes-role of the adipokines. Current Molecular Medicine 2005; 5(3): 333-339. https://doi.org/10.2174/1566524053766022

[44] Huang $\mathrm{Y}$, et al. Decreased circulating levels of tumor necrosis factor- $\alpha$ in postmenopausal women during consumption of soy-containing isoflavones. The Journal of Clinical Endocrinology \& Metabolism 2005; 90(7): 39563962. https://doi.org/10.1210/jc.2005-0161

[45] Penza M, et al. Genistein affects adipose tissue deposition in a dose-dependent and gender-specific manner. Endocrinology 2006; 147(12): 5740-5751. https://doi.org/10.1210/en.2006-0365 
[46] Gong L, et al. Inactivation of NF-k B by genistein is mediated via Akt signaling pathway in breast cancer cells. Oncogene 2003; 22(30): 4702-4709. https://doi.org/10.1038/sj.onc. 1206583

[47] Chiang H-S, et al. UVB-protective effects of isoflavone extracts from soybean cake in human keratinocytes. International Journal of Molecular Sciences 2007; 8(7): 651661.

https://doi.org/10.3390/i8070651
[48] Valsecchi $A E$, et al. The soy isoflavone genistein reverses oxidative and inflammatory state, neuropathic pain, neurotrophic and vasculature deficits in diabetes mouse model. European Journal of Pharmacology 2011; 650(2-3): 694-702.

https://doi.org/10.1016/j.ejphar.2010.10.060 